\title{
Contribution of Blockchain Applications on the Economy in Global Logistic
}

\author{
Selminaz Adiguzel \\ Harran University, Turkey \\ E-mail: sadiguzel@harran.edu.tr \\ "This article was presented as a paper at the Mardin congress 2019"
}

\begin{abstract}
After Industry 4.0 innovations in Logistics 4.0 are increasing day by day, while human intelligence adds a new one to innovations in international transportation. Nowadays, the implementation of Blockchain platforms in the supply chain in the global market is strengthening the supply chain's weak links. With the smart contracts that will accelerate the global market logistics, everything from the cargo shipment to the payment methods on the internet is transparent, making the work of the supply chain actors accountable and reliable.

The aim of this research is to investigate the contribution of Blockchain to the economy in global digital commerce and logistics.
\end{abstract}

Keywords: Blockchain, Industry 4.0, Logistics 4.0, Supply Chain.

DOI: $10.7176 / \mathrm{JSTR} / 5-10-13$

\section{Introduction}

The price of a good, a service used in the debt relationship, is a means of change. In the past, many commodities have been tried to replace money since goods and goods have been exchanged with goods and services. Credit cards, checks, bills, etc. instruments used in foreign exchange transactions, gold, silver money, even though the value of money is not equal to the value The currency, which has a high liquidity compared to other means of exchange, also carries the national elements. In the definitions referring to the concept of money, it is emphasized that the written paper or metal object, which is used as a means of payment, is printed by the state and used as a means of payment. Money, which was used as a tool since the first days of humanity, increased the hostility of the parties and the use of objects such as copper, gold and silver became widespread among the people. Coins used in historical course,

Coins used in historical cruising, 1. Coins or metal coins. 2. We can divide the money into three, which is fully representative of the currency, and the third currency (debt securities, debt securities)-(Hasan Doğan 2018, , S.2, S.225-253. 227 ).

When we examine the money as a system:1. Gold as the only metal system, bullion, exchange system as a reliable exchange tool in the world economy.

2. Silver Standard (Silver Single Metal System

In the supply of money until the spread of gold, the silver mine was largely decisive. In this system, while the weight and adjustment of silver coins were determined by the state, there were significant differences between real and nominal values over time.

3.Bimetallism (Double Metal System)

It is the system that allows the currency standard to be transformed into gold and silver in which both the gold and silver are adopted.

4. Paper Money System

In the paper money system, money is the property of the state other than the property of property, and carries the title of money.

According to Mc Kinsey Global Institute analysis (2013), 12 disruptive technologies will significantly change the situation in the global market by 2025 . Their potential economic impact is estimated to be between 14 and 33 trillion US dollars. These 12 high-potential technologies discussed in the Institute's analysis do not include Blockchain. Nonetheless, even though being out of the list, Blockchain might 
become a dark horse in the competition, because it will influence most of the listed technologies, i.e. Cloud, Internet of Things, and Autonomous cars (Egvenli, 2017, s 5).

\section{Objective}

The aim of this article is to investigate the applications of the block chain in the logistics sector.

\section{Article's Structure}

We explained how the use of the blockchain could emprove efficiency in logistics we reviewed literature that provides a theoretical framework to examine how the blockchain could affect to day's logistics. All of the before mentioned will be done by using already existing literature. The aim of this essay is to provide a comprehensive understanding of the block-chain's possible applications and challenges.

\section{Electronic (Digital) Money Concept}

The popularization of the internet, digitalization, rapid spread of e-commerce with crypto, and currency, ripple, bitcoin, litecoin, IOTA, ethereum, bitcoin cashstellar, litecoin, , Cardano, Monero, EOS, Nextcoin, Darkcion, Norecion, Counterparty, Dogecoin, Litecoin Many electronic encrypted coins such as Anocion, vb provide the liquidity in virtual markets with password from virtual purses.

\subsection{Crypto Money And Bitcoin}

The exchange rate difference that changes every day in the world affects the economy. M. Ragip Görgün, Abdulkadir Barut conducted a survey on economy in 2017 in Turkey 19802015 data collected by least squares of different models have been created. In the models, İt was determined that the increase in the exchange rate increased the imports inflation and foreign trade deficit, the increase in the exchange rate decreased the exports and finally the exchange rate increased the inflation. Cripto money is one of the researches conducted to prevent exchange rate differences that dominate the world economy. Blockchain, the technology underlying bitcoin, is a type of Distributed Ledger Technology that has been defined as a "distributed, shared, encrypted database that serves as an irreversible and incorruptible repository of information" (Wright, 2015, 8-9).

Crypto-currencies provide effective technological development, while money markets affect financial resources. According to World Bank data, there is 180 kinds of currency and is spread through the use of common crypto paracrine cards in the world. E-commerce, in all areas of trade exchange, as a last means of exchange instead of cash in law offices are located in the global world (CoinTürk, Erişim Tarihi 21.11.2018).

Firstly, the technology became well-known in 2008 when it was conceptualized by either an individual or a group of founders of Bitcoin under the name of Satoshi Nakamoto in a research paper titled "Bitcoin: A Peer-to-Peer Electronic Cash System". Blockchain was used as a core component for Bitcoin crypto currency. There, the concept of technology was referred to as "block" and "chain". By year 2014, Blockchain had become a term which is referring to new applications of the distributed database (Kariappa 2015.). On some websites, it is published which companies accept cryptos. Nowadays, companies are kept without the main ledger of their data. Even a simple procedure requires a series of actions between the parties. These virtual currencies, which we cannot keep in the wallet, can be spent using a password: Blockchain was mentioned for the first time in the Bitcoin research paper (Nakamoto, 2008). The definition in 2008: was basic and straightforward, i.e. Blockchain is a technology which runs Bitcoin. However, this definition lacks important details. The Blockchain is a chain of connected blocks that consist of data about transactions. Each block has the hash of the previous block, timestamp and transactional data (Figure 1). When the block is completed with transactions, a new block is created and it contains the same attributes and hash of the previous one (Evin, p 11).

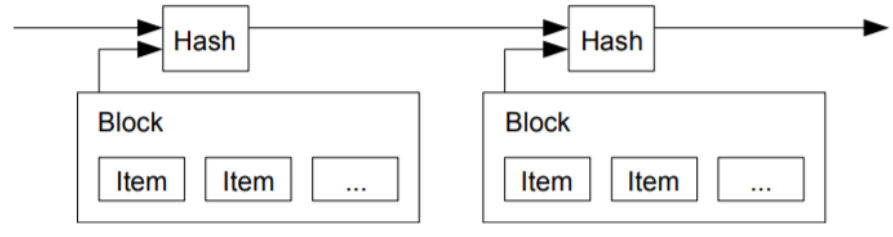

Figure 1 Blockchain Currency Source Evin, p. 11. 
This virtual currency, which is not managed by any bank or organization such as the Central Bank, can establish itself a new stock exchange and offer it sometimes high, sometimes low value. It is possible to send money with digital password/signature secure password (Crypto), without showing any money transfer to any part of the world. The value of the bitcoin demand, which is determined by supply and demand, also increases the value. A limited number of commercially available bitcoins are valued according to a given limit.

Bitcoin, which had a few centimeters of value when it was first launched, came into the market on January 3, 2009 and 1 bitcoin reached the value of 446 dollars. Bitcoin is the non-insured, cryptic, crypto-money that has no authority to assume the responsibility that has not been determined by an official / private institution. There is a general conviction that Bitcoin purchases are not secure .but In 2017 it is discussed that blockchain is very important for economic social system

It is only in circulation with technology. The password is solved with bitcoin shopping, if the password can not be purchased with bitcoin money. Because the person you are shopping with is not the bank, the institution is questionable. Although widely used in the world, some countries, such as Finland, have declared that they will not be considered as currency. There are currently 1565 different types of crypto money in the market and this number is increasing day by day, Bitcoin can be processed via the internet or via mobile applications and can also be processed from the ATM. In spite of all these adversities, IDC will reach the highest values in the American market research in America and in Western Europe in 2021 with the blockchain utilization rate targets.

These virtual currencies, which we cannot keep in the wallet, can be spent using a password. Without a centralized peer-to-peer (P2P) network, electronic payments can be made from one side the blockchain technology, which is the substructure of the crypto money that enters into our lives from the purchase to the purchase of a service even though it is not used in national currency, is seen as a digital technology that can be used in all service sectors. In 2010, the system produced 184 billion bitcoins by itself, and many users' bitcoins were not legitimized by government agencies because they were not safe at the time of their disappearance. According to the 3rd paragraph of Article 3 of the Law on Payment and Securities Settlement Systems, Payment Services and Electronic Money Institutions Electronic funds issued by the issuer of money, exported electronically, stored electronically, used to perform the payment transactions defined in this Law and electronic money refers to the monetary value accepted by natural and legal persons other than the issuing organization.

In the substructure of crypto coins, block chain structure is located. Without a centralized peer-to-peer (P2P) network, electronic payments can be made from one side to the other, and transaction logs are kept as local copies in the databases on each node.

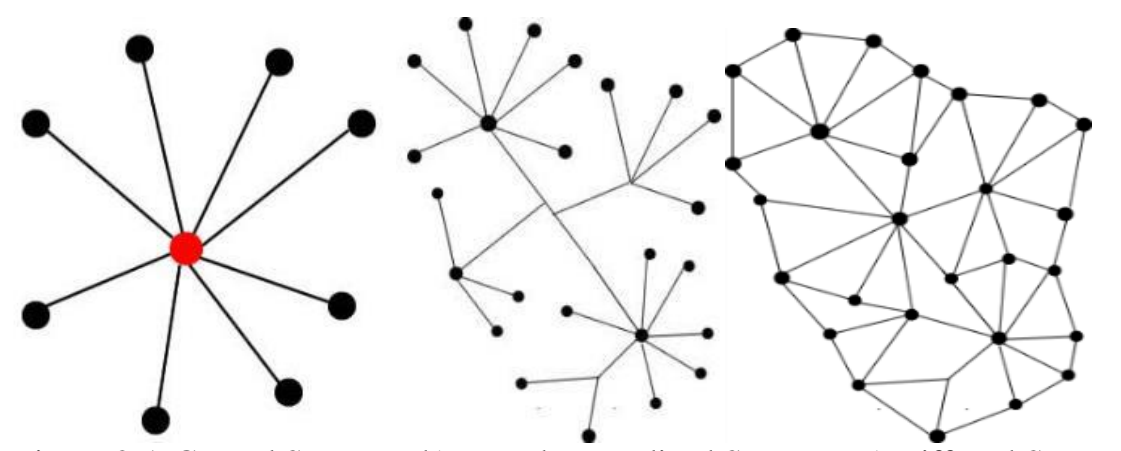

Figure 2.A Central Structure b) Non-decentralized Structure c) Diffused Structure Source: Oğuzhan Taş, Farzad Kiani 2018, p 374.

The block chain is a shared and synchronized data structure copied between consensus algorithms and many sites, countries and / or institutes. All transactions between states, universities, companies, hospitals can be kept in the block chain. The evolutionary development process of the block chain divides resources into three parts:

- Block Chain 1.0 - Money transfer, wire transfer and digital payment;

- Block Chain 2.0 - With the development of Smart Conventions, in the markets and financial transactions such as stocks, bonds, futures, loans, mortgages

- Block Chain 3.0 - Apart from money and financial markets, government, health, science, culture and art are used in the fields ( Taş, 2018: 374). 
Next-generation technologies, such as smart grids, Internet of Things (IoT), smart cities, inter-vehicle networks, health data management applications, will develop through block chain and reconciliation protocol. In the blockchain chain where no records are deleted in the world, a user's name, how much he / she paid his credentials, and how much investment he has, cannot be seen by anyone in the system. The sensitive data in the blockchain chain is protected by encryption. You can invest in finance by signing an electronic contract with peer to peer electronic cash system as one of the rings of millions of users. Before making a transaction with Bitcoin, an electronic contract is made with the user name and e-mail address.

Like Bitcoin, subcoins such as Nextcoin, Darkcion, Norecion, Counterparty, Dogecoin, Litecoin, Anocion and many other currencies are now entering the market quickly. Thanks to Blockchain technology, transactions are performed on complex accounts and numbers. The fact that the amount of money sent by whom is not known makes it easier for those who send illegal money. The BDDK in Turkey, which are not issued by any public or private organization and is known as a virtual currency Bitcoin is not assured for the money, are not considered as electronic money under the Act as the current structure and functioning. Bitcoin is not considered legal in Turkey not prohibited entirely. The state cannot receive taxes from these unlawful coins (Aslantaş, 2016: 361).

Crypto money investments, which are frequently seen as games on the internet, are being tried to be put on the legal basis by the state. Although e-commerce is not preferred because it is not safe at first, many companies adapt to the trends and make international trade safe trade through e-commerce. Every day innovations are added to the world and every innovation is initially faced with resistance. For security reasons, many people are cautious not to lose fear of losing everything as a result of hacking out of the password, so many companies have left their cash places to their credit cards in the future by means of trade, as well as documents such as bonds, bills and checks, along with the banking system.

\section{Blockchain Technology in Logistics Sector}

Blockchain technology, which is the substructure of the crypto money that enters our lives from purchase to service purchase, is seen as a digital technology that can be used in all service sectors, and is used by logistics companies in Germany, France, EU countries, China and Russia USA. In 2010, the system produced 184 billion bitcoins by itself, and many users' bitcoins were not legitimized by government agencies because they were not safe at the time of their disappearance.

According to the 3rd paragraph of Article 3 of the Law on Payment and Securities Settlement Systems, Payment Services and Electronic Money Institutions 1k Electronic funds issued by the issuer of money, exported electronically, stored electronically, used to perform the payment transactions defined in this Law and electronic money refers to the monetary value accepted by natural and legal persons other than the issuing organization. Electronic money organization according to paragraph d of the article: This law represents the legal entity authorized to issue electronic money under this Law. In Turkey, which therefore crypto currencies Bitcoin etc. are not considered legally as electronic money. According to Article 4

(1): "The system is operated by the system operator. According to the Bank and Article 5 of this Law, persons other than those who have an activity permit cannot operate as a system operator.

(2) Rules and agreements regarding the operation of the system and participation in the system shall be determined by the system operator in accordance with the regulations to be issued by the Bank.

(3) The Bank is authorized to make the necessary arrangements to ensure that the systems operate smoothly and without interruption banka, as the bank or public legal entity is not shown as the legal representative of the crypto money, so crypto money is not a legal money and a legal form of payment. The state, which is the dominant power, cannot collect taxes from these forms of payment. However, it is not legally a crime to deal with crypto money". In Western Europe,

$46.7 \%$ of blockchain applications are in the banking sector,

The second is logistics 3 . in the manufacturing sector,

4. It is stated that the industrial sector will be used in public institutions in the fifth place In terms of technology spending,

68 percent of the Western European block chain goes to services (IT services and business services). By 2020, the European Commission will finance projects that can benefit from blockchain technologies up to EUR 340 million. 
Bitcoin assigns bitcoin mining to a person at one end of the application, and as individuals decode bitcoins, they encounter more and more difficult passwords and become bitcoin miners (Bc. Ondrej Mulár, Brno, Spring, 2018).

Depending on how is a blockchain network operated and who can join this network, two categories can be recognized:

- Public blockchains

- Private blockchains

\section{1 Public blockchains}

Bitcoin, as the first blockchain implementation is a public blockchain. Participation in a public network is entirely open and free. Anybody with a computer on which specialized software of particular blockchain can run, can join and participate in that network. In most cases, required software is publicly available, often as open source. Crypto currencies are the most popular and widely used applications of public blockchains. Bitcoin was the first one, but since its release, hundreds of new cryptocurrencies were created and are still operational

\subsection{Private blockchains}

A private blockchain is a blockchain which is running inside a network composed only from authorized nodes. This restriction is usually achieved by different genesis block. Genesis block is the first block in the chain. If two nodes have different genesis blocks, they have completely different chains, because they don't have any common subchain. Therefore they will not accept the chain of the other node. Private blockchains are often used as testing instances for various blockchains. In cryptocurrencies supporting smart contracts (see Section

2.4 for more info about smart contracts), private instances areused for their testing, before deploying them into the public chain. Blockchain communities view the private blockchains as the distributeddatabases with the full history that cannot be changed In entirely private environment controlled by only one entity, private blockchains have small or maybe no sense as the entity owns 100 $\%$ nodes.

You can buy. We buy tickets on an app or the railway company web. The credit card company takes a cut for processing the transaction. With blockchain, not only can the railway operator save on credit card processing fees, it can move the entire ticketing process to the blockchain. The two parties in the transaction are the railway company and the passenger. The ticket is a block, which will be added to a ticket blockchain. Just as a monetary transaction on blockchain is a unique, independently verifiable and unfalsifiable record (like Bitcoin), the final ticket blockchain is also a record of all transactions for, say, a certain train route, or even the entire train network, comprising every ticket ever sold, every journey ever taken.

But the key here is this: it's free. Not only can the blockchain transfer and store money, but it can also replace all processes and business models which rely on charging a small fee for a transaction. Or any other transaction between two parties.

\section{Where Blockchain is Used}

BLOCKCHAIN is used in many areas. One of them is Financial markets. In the U.S. Canada and Japan, there is a 3-day settlement cycle, and in the EU, Hong Kong and South Korea, this cycle takes two days (Peters et. al 2015, 26). This one-day difference can bring many risks related to liquidity and credits.

That is why in the U.S. the Federal Reserve pressed all stakeholders to act on increasing end-to-end payment speed (Kiviat, 2015-2016, 585-586). Some argue that blockchain does not only move value, but it also integrates several components of the trading-clearing-settlement value chain in an elegant and efficient way (Kiviat, 2015-2016, 569, 587).

1.Therefore, the sphere of clearing and settlement trades is one of the potential applications for blockchain. For this reason, blockcahain has become one of the forms of payment in logistics.

Santander UK in June 2016. (Kakavand et al., 2016, p 16).

Particularly in the U.S., non-depository financial services such as blockchain payment companies have been traditionally regulated. Department of the Treasury's Financial Crimes Enforcement Network (FinCEN) (Swan, 2015, 22). On the other hand, the EU has a uniform legal framework for regulating electronic money.

2.Smart contracts 
3.Entrepreneurs are now developing a new way of using blockchain - smart contract. It is a contract between parties that is coded and uploaded to the blockchain. The smart contract does not rely on the third party authorities. All processes in dealing with such contracts are automatically controlled. The clauses of a contract are executed after all parties have accomplished their duties. This function removes all ambiguity regarding the execution of contract conditions concerning the existence of external dependencies. (Swan, 2015, 25).

4.Smart contracts may make the negotiation process and performance of a contract easier and more efficient.

One of the main features of blockchain in smart contract is enabling "trustless" transactions. This type of transaction defines as validated, monitored and bilaterally enforced transactions over a digital network. Smart contracts can incorporate multiple digital signature for necessary approval of participants. If the conditions of a smart contract depend upon real world data, systems called "oracles" can be implemented to monitor and verify this data (Krystsina Sadouskayap p 11).

\section{Bitcoin Mining}

The system, which was set by Nakamato in the early days of Bitcoin to 50 bitcoin, will increase gradually and the chance of finding a block is reduced. This figure is decreasing day by day. So mining is getting harder every day and requires more processing power The most important point that makes Bitcoin and the block chain so important for technology and a great invention is the work system known as Proof-ofWork.

\section{Blockchain Association (BITA)}

In South Korea and Seoul, the international logistics company Lotte joined the BITA Blockchain Association and joined the Origin Trail, a company that aims to build the supply chain and blockchain standards (Yildırım,2015, s.89.).

Lotte, which has more than 400 members in the world, has a warehouse management, airway, highway, railway, transportation modes, cargo services, 15 mega terminals, 90 regional dealers and a giant logistics company serving the USA, Asia and Europe, the blockchain in Transport Alliance ( Blockchain Union in Transport, BiTA participated)..

BITA was founded in 2017 with the aim of developing and promoting Blockchain standards for global transport and logistics companies. The main purpose of the association is to increase the use of blockchain applications in the transport and logistics industry, as well as to create the necessary industry standards for the adoption of technology. The Union uses the OriginTrail application, which is specifically designed for blockchain-based supply chains, and has over 400 members(Koin Bülteni, 2018) .

The blockchain technology, which is the substructure of the crypto money that enters into our lives from the purchase to the purchase of a service even though it is not used in national currency, is seen as a digital technology that can be used in all service sectors.

\section{Blockcoin and Bitcoin in The World}

\subsection{Blockcoin and Bitcoin in US}

The use of crypto money in the US as a means of payment is also common in the state of Ohio. Enterprises entering "www.Ohiocrpto.com" can pay their taxes by bitcoin. US Treasury Secretary Steven Mnuchin, a 24-year-old investor in Chicago-based Consolidated Trading, stolen $\$ 2$ million to help offset margin trading and personal losses in the crypto market, and US Treasury Secretary Steven Mnuchin said that the biggest risk for digital currencies was the crypto currencies of terrorist organizations and criminal networks. Noting that his country should use it for bad jobs, he will work with other G20 members to ensure that digital currencies such as Bitcoin will not turn into ve Swiss bank accounts ". The US Securities and Exchange Commission (SEC) has refused to apply for virtual currency Bitcoin to be an Exchange Traded Fund.

According to Rick Burnett, CEO of LaneAxis, working in the US for this purpose, the patented system will turn the cycle of unloaded trucks around the world. Forbes Insights Survey According to a Forbes Insights survey conducted by more than 400 senior executive-oriented executives in 2018 , 65\% believe that logistics, the supply chain and the transport sector have experienced nothing but a tectonic change. Although there are several drivers behind this shift, one of the most powerful ones is the advancement of the behind-the-scenes technologies such as artificial intelligence (AI), machine learning (ML), and 
increasingly block-chaining. Although it is expected to generate more than $\$ 15$ trillion in international transportation by 2023 , more than $\$ 800$ billion in revenue generation, chaos, fraud and inefficiency in the US logistics area can be prevented with blackchain.

In USA again, a logistics company Lane Axis tries to eliminate the brokers of 3rd party logistics by creating a blockchain chain based on logistics supply chain based on blockchain technology The Robotiba Platform, established in Slovenia in 1990, plans to reduce energy consumption in the country by $20-30 \%$ thanks to Blckchain Technology. The aim of the platform is to connect large consumers and corporate users to the Robotina Platform. Energy consumption of those connected to this platform will be reduced by an estimated $30 \%$. To ensure the transparency, traceability and security of the entire network and community, an additional feature, Robotina Utility Coin (ROX), will be implemented and members will be allowed to receive something and services at a $3 \%$ discount rate in a virtual market and will It will enable them to achieve benefits. The Robotina Platform will be crypto-friendly and the Robotina Utility Token (ROX) will be a special tool used in all internal processes. The user will receive a special discount when paying with the ROX (one of the ROX service features), while the services and products sold on the Robotina platform will also be available with other crypto currencies, tokens or fiat currency. Other forms of payment will be converted into ROX tokens and designed to finance community-earned benefits. A public Initial Money Offer (ICO) will be held in March 2018 to collect contributions from the sponsors (28.5 million Euro - Hard Cap) and reward them with ROX tokens. After the ICO (May 1, 2018), all 815,000,000 ROX tokens sold will be produced. Subsequent issuances will be disabled forever in the smart contract.

According to a study conducted at Cambridge University in 2017 on the increasing bitcoin usage of each passing day, there are 2.95 to 5.8 million people who have a crypto money wallet. The only concern is security because there are reservations at a time that are rich and there is a risk of losing everything at once. In the United States, voting in the state of West Virginia with the mobile blockchain security provider is a sign that the use of Blockchain technology will become widespread.

According to the 3rd paragraph of Article 3 of the Law on Payment and Securities Settlement Systems, Payment Services and Electronic Money Institutions 1k Electronic funds issued by the issuer of money, exported electronically, stored electronically, used to perform the payment transactions defined in this Law and electronic money refers to the monetary value accepted by natural and legal persons other than the issuing organization.

\subsection{Bitcoin in Turkey}

First, 4. Bitcoin platform BTC Turk and Koinim exchanges in the world, bitcoin purchases and sales operations. In these platforms with close to 500,000 members, a certain percentage of operating commission is charged for the sale of the crypto money, which has risen from 2000 to 20000 rubles since 2009. As there are no controllers such as the Capital Markets Board or the Banking Regulation and Supervision Agency, the persons on this platform do not have a specific legal entity who will pay the losses that people will incur when they close their internet addresses. Bitcoin ATM in Istanbul Ataturk Airport shows that it is used in commercial transactions even if the bank is not as a currency. In 2013, when China and the Russians installed bitchoin data centers, the value of bitcoin increased. Korea is among the countries that do not accept Bitcoin as currency. innovative studies for the establishment of research laboratories in Turkey TUBITAK Blockchain leadership are trying to be followed. As long as the adoption of the Internet takes years and the use of blockchain technology, the use of blockchain technology will become widespread in the field of logistics as in many other areas. airline ticket sales are also taking advantage of the technology in Turkey blockcha blockcha do with the technology. The company has branches in 141 countries and operates in commercial transactions with crypto Money (uçuracak.com Acsesed Date 12.06.2019).

\subsection{Bitcoin in Europe}

In Norway, Germany does not consider bitcoin as a currency. Already the Euro currency is the goal of the existence of the EU. It is not in accordance with the philosophy of the union that the European Union is considered to be a single currency, because it is in the philosophy of the European Union. However, the EU does not completely reject the currency that changes the financial transactions in the world. According to the US based market research (Internationale Data Corparation). Blockchain spending in Western Europe in January 2018 is estimated to increase to \$ 1.8 billion. According to research of this research firm, blockchain will be traded by banks in Europe in 2018, and 46.7 percent of 2018 blokchain 
expenditures are expected to come from the banking sector. The European Union supports projects by allocating 300 million Euro for the rapidly spreading Blockchain in 2018. 22 European countries came together and established a blockchain partnership. The European Commission initiated the rup EU Blockchain Observatory and Forum Komisyon which was supported by the European Parliament. The EU Commission seeks new opportunities for the blockchain, while also monitoring the trends and leading the countries. In an open forum, citizen, expert and auditor software developers are trying to create a consensus by bringing the state authorities together in a forum. There are efforts to develop solutions to the concerns that will be evaluated from the stakeholders with the $\$ 500$ thousand budget. Although it is a pilot project, usage scenarios are followed to follow EU blockchain applications.

\subsection{Russia and China}

It has been used in money laundering in drugs and smuggling in countries such as Russia and China, and it does not reduce the value of bitcoin. Monetization with bitcoin is a way for people who want to become rich. In Shanghai and Beijing, 32 policies on blockchain chain across the country have been published. Blockchain technology in Shanghai and Beijing focuses on innovation and security to serve the real economy. The Chinese Central Bank and the Chinese government warn the public that the blockchain is not safe. The China City Blockchain Industry Association in China, the Hong Kong Blockchain Industry Association and Macau University Innovation Center, together with the newly formed alliance, bring together 54 different companies. This study covers blockchain technology in areas such as funding, finance and trade. The aim of this coalition is to enable the development of the blockchain industry in China. Industry, technology, service platform to develop a blockhain platform to establish Despite all these efforts, the Chinese government, such as the United States, not to give crypto money to give information about operations (cin Türk Acsessed Date 12.04.2019).

\section{The Use of Blockchain Technology in the Supply Chain}

There are also three main ows in supply chain: material flow, information and capital flow. Material flow is concerned with the transfer of the physical product from the supplier to the customer via a carrier. Information ow is the digital thread that documents the transfer of the product. This digital thread includes the order information and the shipment information (e.g., shipment status, GPS location, etc.). Capital flow is concerned with payment and transfer of the ownership of the asset. Supply chain visibility refers to the accurate and real-time delivery of information to all stakeholders. The benefits of an increasing supply chain visibility include

reduced business and supply chain risks, improved lead times and performance, and early identifcation of shortage and product quality problems Lack of visibility and transparency can cause inaccurate forecasting and unexpected delays leading to increased product cost. The blockchain technology is used to enable supply chain visibility by combining a set of distributed databases. These databases implement a public ledger which contains an immutable business record for all the events in the physical distribution phase of supply chain. Custody events have corresponding entries in the public ledger. These entries consist of the Event ID and the Event Hash value. The validity of the custody events in the private ledger can be veri_ed by comparing them to the correspond entries in the public ledger. The monitoring events are chained with the publicversion of the genesis events and custody events in the pubic ledger. This approach improves the validity of the information in the public ledger.

There are several areas for future extension to the proposed framework. These include:

Block verification: Several enhancement to the block verification can be considered.

First, the dificulty of the computation of the hash value for a block needs to be investigated and the number of events in a block needs to be adjusted accordingly. In addition, mechanisms should be developed to handle block collision resulting from multiple blocks being received at the same time.

In Bitcoin, duplicate blocks are also chained to the blockchain and each branch is allowed to grow as more blocks are received. The nodes in the network only consider the longest blockchain. Overtime, only the longest chain will survive. Monitoring event verification: Shipment location information is collected by third-party monitors. Relying on a single monitoring event may not infer suficient reliability. Multiple monitoring events are needed. In fact, the level of trust of the public ledger is directly proportional to the number of monitors involved in the network and the number of sighting of a given truck. Analyzing the trust level of the public ledger based on the number of monitoring events is an area for future work. In conclusion, the proposed framework is a cost-effcient and scalable solution for supply chain visibility. Even though the system is still in the prototype phase, it demonstrates the ability of the framework to 
deliver field information to all stakeholders in pseudo real-time. The blockchain technology is a current trend in supply chain system. We believe that the proposed architecture is a practical solution that takes into consideration business requirements.In the transport sector, the sender requests logging into the blockchain network. The carrier adds the route, the type of transport to the proposal. Invites other carriers from the Blockchain network. Other carriers offer freight, insurance, and fare tariffs via the blockchain. The shipper and carrier agree on the terms ( Haoyan Wu, 2017i p 12).

Smart Contract There are usually two to three rounds of negotiation. The contractor shall sign the contract electronically in the carrier while the contract is being tendered. Once finalized, the sender begins to send the loading auctions. The carrier accepts loads and provides location update. The carrier sends the invoice for completed freight transactions. The sender verifies the invoice and pays for the completed loads ( alliance-plans-development-of-four-finance-oriented-platforms Erişim Tarihi 21.11.2018).

All this information here Blockchain is stored securely and invariably on the distributed database and all information is clearly monitored by all parties involved in the contract In order to use this technology in the supply chain and logistics processes, a very robust information technology infrastructure needs to be allocated. The integration of this technology to the parties in the consortium of the established consortium is also important for the simultaneous sharing of information.

In addition, this technology requires an initial level of knowledge, skills and expertise for users, and users should also be given Blockchain training ( UTIKKAD, 2019). In the supply chain, the information that the foodstuffs to be transported in the cold chain can be conveyed under the circumstances, ensures that the substances that are required to be carried with care are informed to the stakeholders in the chain of the transport of the dangerous goods. The future of logistics is influenced by digital transactions, innovation, logistics 4.0, exchange rate changes and economic policies. The survey of Istanbul University and Sakarya University in 2018 is important in terms of revealing the effects of blockchain technology on industry. The survey was applied to 109 different logistic companies. In the Transport and Logistics Sector Questionnaire which consists of 26 questions to measure the current situation and future trends of Transport and Logistics service providers, and to determine their ideas / suggestions / opinions, the subjects were asked the question of which of the technological developments will affect the future of the transportation and logistics sector more. The answer to the questions given in the questionnaire is given in the graph below. The subjects stated that $9.5 \%$ blockchain technology affects the logistics sector (Sakarya Üniversity, 2018).

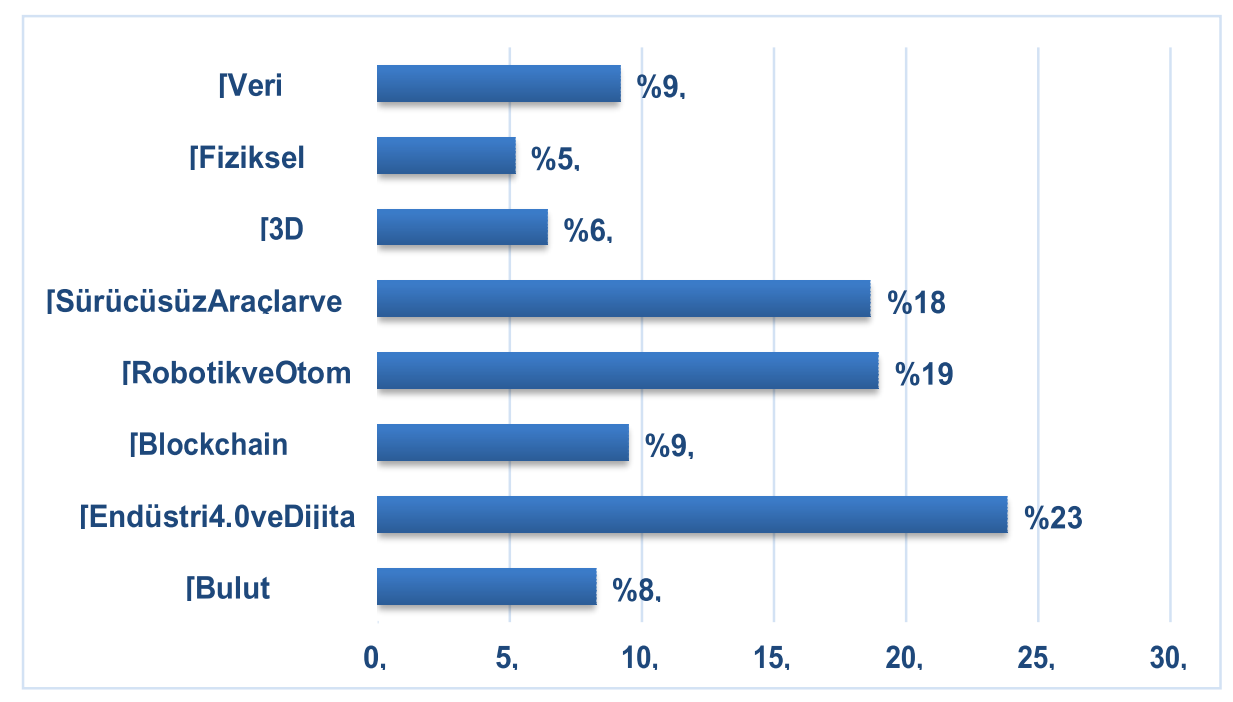

Figure 3. Transportation and Logistics Report Source Transportation and Logistics Report

2018 The Blockchain technology has the potential to eliminate the trade barriers on sectors such as customs clearance, logistics, trade finance and transportation, according to the WTO's ine Blockchain and International Trade: Recommendations for Opportunities, Challenges and International Trade Co-operation. It was stated that the elimination of obstacles caused by Blockchain could lead to 
more than $\$ 1$ trillion in new trade, and to bring world trade to a smarter right. Thanks to Blockchain technology, all the transactions made by the companies in the book are kept in the database. As a summary of the foregoing, the following table presents the principles of Blockchain technology.

Table 1. Blockchain Principles Distributed Database Each side of a blockcha has access to the entire database and is fully maintained.

Table 1. Blockchain Principles

\begin{tabular}{|l|}
\hline Distributed Database \\
Each side of a blockcha has access to the entire database and is fully maintained. \\
\hline Peer to peer transmission \\
Communication takes place directly between peers on a central node, . \\
In other words, each node stores and transmits information to all other nodes. \\
\hline Transparency \\
NicknameAll process, value, can be seen by anyone with access \\
The system means that each node or user has a unique 30-character alphanumeric \\
has the address that describes it \\
When a process is entered in the database and the accounts are updated, \\
\hline Records cannot be changed, \\
Several computational algorithms and approaches have been deployed. \\
Source: Blockchain for and Logistics: What to Adoptand.
\end{tabular}

Peer to peer transmission Communication takes place directly between peers on a central node, in other words, each node stores and transmits information to all other nodes. Transparency NicknameAll process, value, can be seen by anyone with Access The system means that each node or user has a unique 30-character alphanumeric has the address that describes it When a process is entered in the database and the accounts are updated, Records cannot be changed, Several computational algorithms and approaches have been deployed. Source: Blockchain and Logistics: What to Adoptand Blockchain can help overcome problems in logistics and increases efficiency in chain processes. In particular, the use of technology facilitates access through relevant stakeholders across the supply chain, thanks to data transparency. Also, the blockchain can help you realize cost savings. Activates simpler, more automated and error-free processes, accelerating physical flow of goods Thanks to the maritime area .Blockchain technology in the maritime area. tractors, containers followed by a block chain with the blank instead of moving around my site is sent to a registered place there to load the path is planned to continue. With this software, millions of dollars are planned to be made all over the world. Most governments have committed to reducing their carbon dioxide emissions by 2020 by increasing their renewables in their portfolios and using the smart grid concept. New technologies and connected devices are widely accepted, and new platform-based jobs outperform traditional ones. CEVA, which follows innovative applications such as Blockchain, has been used in port operations, terminal operations and customs operations with TradeLens software which is developed by logistics company. In cooperation with IBM and Maersk, CEVA Logistics provides the logistical management and contracting internationally in accordance with the glocal standards.

Lotte Global provides services in many fields ranging from warehouse management to import / export transportation, customs operations, package distribution service, airway, railway and truck transportation. Lotterrs cargo services in Korea consist of 15 mega terminals, 90 regional dealers and more than 1000 local offices, and in addition, it has organizations in America, Asia and Europe. FreightWaves emphasizes that Lotte Global has already developed a smartphone application for its services and is also investigating the cargo services provided with the drone. Lotte, South Korea's leading logistics company, has joined the Blockchain Association of Transport (BiTA). Thus, BiTA has reached more than 400 members with new participation. South Korea-based Lotte Global Logistics has announced to the world that it is working in cooperation with the BiTA blockchain Union. With the Blockchain technology, it is possible to manage the warehouses and to transport empty containers that will be easier._However, it is too early to say what the blockchain technology will exactly enable and when the blockchain can be implemented to the financial sector, since the development of the technology is in its early stage. Nevertheless, it has great potential to disrupt the current financial system. Without unnecessary and pricey intermediaries in e.g. in-ternational payments or securities trading, financial 
institutions can reduce costs and increase efficiency. Furthermore, since blockchain-based processes tie up less capital, risks are reduced (The Economist, 2016).

\section{Conclusion}

Although crypto money is not legally accepted today due to security problems, it is expected that the technological network of crypto money will become a network traded by public legal entities. Many countries around the world are setting up platforms for crypto currency.It expects technology to be safe, and does not allow it to be legally used as a currency, Even though it is no stranger to the money. Because money also represents the nationality of a nation. In the future, Blockchain will help Europe and its member states to redesign their information systems, promote user confidence and the protection of personal data, create new business opportunities and create new leadership areas for citizens, public services and It is considered as a great opportunity for companies to benefit. Using blockchain technology in all chains of the supply chain is far from imagination. In many countries around the world, new technologies are being implemented and are looking for ways to be very efficient and improve performance in a short time. the Blockcha technology is now very secure for traffickers and drug dealers to send money, tax evasion and secure the fear that hackers will get into does not seem to be an investment. However, as a result of the development of blockchain technology by big companies such as IBM, the spread of the internet in logistics and other fields is promised.subject. It is a technology where every supplier in need can use their performances in a network where every stakeholder needs can be used in the most efficient way on a digital account book and on a platform that is visible to everyone in the network. Technology, humanity offers what they imagine. It is important to develop software, to monitor and audit transactions by state institutions and to tax all transactions done from past applications to the scope of audit since the use of this technology to be strengthened will be beneficial to the sector as the problems seen in the application are eliminated and legal regulations are enacted.

There are wars in the world. All kinds of financial aid to the underdeveloped countries during the war, instead of being sent through banks, sending via blockchailn means that the ways that do not give identity to the money will be preferred in the future. In addition, the crypto currencies that did not enter the wallet began to be used as exchange instruments while new searches were going to take place to replace the currencies such as dollars, Euro, which have a say in the world. In the coming centuries, it is thought that new means of change will be on the agenda of the economic agreements where the nationality of money will be abolished.

\section{References}

Ateş Aslantaş, B. (2016), Crypto Currencies, Bitcoin and its Accounting aseb, Çankırı Karatekin University, Journal of SBE, 7.

Bilgili, Y. (2014). Macroeconomics Lecture Notes. Istanbul: Second Page Publications. Bc. Ondrej Mulár, Brno, Spring

https://robotinarox.io/wp-content/uploads/2018/11/Robotina_WP_TR.pdf (Acsessed Date 11.11.2018).

Bc. Ondrej Mulár, (2018,) Blockchain Technology in the enterprise environment Masaryk University Faculty of Informatics Master's Thesis,

Boyes, W. \& Melvin, M. (2013). Fundamentals of Economics, (Trans. E Telatar), Ankara: Nobel Publishing

Çağlar, Ü. (2007). Gisi Electronic Money: Developments in Information Technology and New Payment Systems Tekn, Journal of Social Sciences.

Görgün Mehmet Ragıp \& Abdülkadir BARUT, (2017) Relation Between Current Account Deficit and Exchange Rate, Its Effect on Import, Export and Inflation: An Ampirical Analysis for Ind International Symposium On Economics, Politics And Administration Isepa . 
Fatih Yıldırım (2015) Crypto Coins, Block Chain Technology and Possible Effects on International Relations, Journal of Civilization Researches, Volume: 2 Number: 4 Year: (Download Date: 21.11.2018).

Hasan Doğan (2018) Crypto Coins and Blockcha's Encryption Technology in Terms of Islamic Law, Selçuk University Faculty of Law Journal, C.26, S.2, S.225-253. 227 .

Haoyan Wu, (2017), A Distributed Blockchain Ledger For Supply Chain, Purdue University Graduate School Thesis, Master Of Science İn Electric And Computer Engineering, Indianapolis, Indiana

Kariappa, B. 2015. "Block Chain 2.0: The Renaissance of Money". Wired. Accessed 27 October 2017 https://www.wired.com/insights/2015/01/block-chain-2-0/,

Krystsina Sadouskaya 2017, Adoption of Blockchain Technology in Supply Chain and Logistics Bachelor's Thesis Business Logistics

Khudnev, Evgenii, (2017), Blockchain: Foundatıonal Technology To Change The World School of Business and Culture Degree Programme in Business Information Technology Bachelor of Business Administration

Oğuzhan Taş, Farzad Kiani (2018). An Investigation on Attacks on Block Chain Technology Istanbul Sabahattin Zaim University, Faculty of Engineering and Natural Sciences, Computer Engineering, Istanbul, Turkey.

http://www.utikad.org.tr/SektorelHaber.aspx?DataID=20988\&Baslik=BLOCKCHAIN\%20TEKNO LOJ\%C4\%B0S\%C4\%B0\%20NED\%C4\%B0R\%20VE\%20LOJ\%C4\%B0ST\%C4\%B0\%C4\%9E $\% \mathrm{C} 4 \% \mathrm{~B} 0 \% 20 \mathrm{NASIL} \% 20 \mathrm{ETK} \% \mathrm{C} 4 \% \mathrm{~B} 0 \mathrm{LEYECEK}$ ?(Indirilme Tarihi 20.10.2018).

Sakarya University, (2018). http://www.ulk.sakarya.edu.tr/wp-content/uploads/2018/05/ Ula\%C5 \%9Ft\%C4\%B1rma-ve-Lojistik-Sekt\%C3\%B6r-Raporu-2018.pd (İndirilme zaman1 22.11.2018).

Laura JUTİLA 2017, The Blockchain Technology And İts Applications İn The Financial Sector Aalto University School Of Business Department Of Economics Bachelor's Thesis Fall,

Oğuzhan TAŞ, Farzad Kiani (2018). A Study on Attacks on Block Chain Technology, Istanbul Sabahattin Zaim University, Faculty of Engineering and Natural Sciences, Computer Engineering, Istanbul,

Organ, I. \& Gölçek, A. G. (2017). 32 Limitation of the Rights and Assignments of the Persons in the Constitution: An Evaluation in Terms of Tax Law g, Ömer Halisdemir University Journal of the Faculty of Economics and Administrative Sciences.

Y1lmaz, Y. (2007). Hukuk Legal Dimension in Cryptology Applications Üniversitesi, Marmara University Faculty of Law, Journal of Law Studies.

http://dergipark.gov.tr/download/articlefile/322413 (Downloads: 15.05. 2018)

https://coin-turk.com/turkiyede-bitcoin-kabul-eden-yerlerin-listesiindirilmetarih o

https://cargox.io/press-releases/cargox-platform-live Downloads 21.11.2018).

www.alliance-plans-development-of-four-finance-oriented-platforms Downloads 21.11.2018). 
http://www.utikad.org.tr/sektorelhaber.aspx?datald=20988\&baslik=blockchain\%20teknoloj\%c4\%b 0s\%c4\%b0\%20ned\%c4\%b0r\%20ve\%20loj\%c4\%b0st\%c4\%b0\% $\quad$ C4\% $\quad 9 \mathrm{E} \% \quad \mathrm{C} 4 \% \quad \mathrm{~B} 0 \%$ 20NASIL\% 20ETK\% C4\% BOLEYECEK? (Downloaded 20.10.2018).

http://www.ulk.sakarya.edu.tr/wp-content/uploads/2018/05/ula\%c5\%9ft\%c4\%b1rma-ve-lojistiksekt\%c3\%b6r-raporu-2018.pdf

www.ucuracak.com Download time 22.11.2018).

http://ticaretgazetesi.com.tr/havada-dijital-para-donemi-basladi (download time 22.11.2018).

https://www.yenisafak.com/ekonomi/yolcular-bitcoin-etherium-ve-ripple-ile-ucacak-3176731

Downloads at 22.11.2018).

http://www.lojistikglobal.net/ Download Time 22.11.2018).

http://www.icohaberleri.com/blockshipping-gscp-denizyolu-tasimaciliginda-yeni-bir-donem/(Date on 11.11.2018).

http://www.mevzuat.gov.tr/MevzuatMetin/1.5.6493.pdf (downloaded 11.11.2018).

https://robotinarox.io/wp-content/uploads/2018/11/Robotina_WP_EN.pdf (Downloads 11.11.2018).

https://www.forbes.com/forbes-insights/(Download date 11.12.2018).

https://koinbulteni.com/guney-korenin-semable-logistics-files-lotte-blockchain-logistics-untilinekatildi- 22529.html (Downloaded from 11.12.2018).

https://www.bifa.org/news/articles/2017/feb/blockchain-technology-in-logistics (Downloaded from 11.12.2018). 